\title{
Anatomical examination of the fibula: digital imaging study for osseointegrated implant installation
}

\author{
Yoshiaki Ide $1^{*}$, Satoru Matsunaga ${ }^{2}$, Jeffrey Harris ${ }^{3,4}$, Daniel O' Connell ${ }^{3,4}$, Hadi Seikaly $y^{3,4}$ and Johan Wolfaardt ${ }^{3,4}$
}

\begin{abstract}
Background: Free vascularized fibular flaps are commonly used in jaw reconstruction. CT scan images of the fibula are used in digital planning of jaw reconstruction. In order to fully describe the anatomy of the fibula, an imaging study of the fibula was undertaken. The purpose of the present study was to examine the anatomical structure of the fibula using patient $C T$ images.
\end{abstract}

Methods: The CT scan images of fibulae of 20 patients were used for the study. The results of the analysis showed that, of the widths, the anterior border of the fibula to the posterior surface was the largest dimension. The shape type analysis showed that the triangular type was most prominent near the head of the fibula, and the irregular type was most prominent towards the lateral malleolus.

Results: The results of height and width related to the long axis of implant installation showed that the width of the central section was the largest. With respect to the length of available bone volume, the length near the lateral malleolus was larger than that near the head of the fibula. The results showed that there were significant differences in size between male and female fibulae.

Conclusion: The present study provides a CT scan based analysis of the anatomy of the fibula. Important information for the optimal site of installation of osseointegrated implants in fibular free flap reconstructions is also provided.

Keywords: Fibula, Free vascularized fibular flaps, Dental implant, Jaw reconstruction, Osseointegrated implant, CT, CT scan analysis, Fibula anatomy

\section{Background}

Free vascularized fibular flaps (FVFF) have been widely adopted ever since Taylor et al. [1] used this method to reconstruct the tibia in 1975. FVFF is also used in maxillofacial regions, since reconstruction of the anatomic dental arch, oral functions, and facial aesthetics are better than with ilium and scapula grafts [2-5]. Osseointegrated implant use in FVFFs has also become common in recent years [6-8], resulting in improved outcomes of mastication, speech, and swallowing functions $[9,10]$. For jaw reconstruction, the fibula is harvested from the donor site by measuring upwards from the lateral malleolus. The

\footnotetext{
* Correspondence: ideaki@tky.ndu.ac.jp

'Department of Developmental and Regenerative Dentistry, School of Life Dentistry at Tokyo, The Nippon Dental University, 1-9-20 Fujimi, Chiyoda-ku, Tokyo 102-8159, Japan

Full list of author information is available at the end of the article
}

point of sectioning the fibula is typically at $8-10 \mathrm{~cm}$ above the lateral malleolus [11].

Successful FVFF requires an understanding of fibular anatomy. As a result, a number of reports have been published on measurements of cadaver fibulae [12-15]. The use of osseointegrated implants in the fibula usually involves trimming a sharp anterior border (anterior margin) and then installing either a regular diameter $(4.3 \mathrm{~mm} \phi)$ or a narrow diameter implant $(3.5 \mathrm{~mm} \phi)$ along the axis from the anterior border of the fibula to the posterior aspect. Analysis of fibular shape with reference to these processes is extremely important from a clinical perspective. While there are reports that take anatomical considerations into account for installation of osseointegrated implants, the information is limited.

When performing osseointegrated implant installation, the dimension of the site for accomodation of the long 
axis diameter of the osseointegrated implant may be measured on preoperative CT images, so that appropriately sized implants can be chosen. Consequently, an understanding of the dimensions of the fibula as assessed from CT images is important for implant treatment. This becomes all more so when fully digitally derived 3D constructs with fully guided surgery are used in advanced jaw reconstruction procedures.

The objective of the present study was to investigate the anatomical characteristics of fibulae with a view toward implant treatment. Using preoperative CT data from patients undergoing lower jaw FVFF reconstruction, the anatomical characteristics (differences according to site and gender) at the site of implant installation, as well as the available bone volume for installing the implants, was investigated.

\section{Methods}

\section{Patients}

The research was performed with the approval of the University of Alberta Health Research Ethics Board (Date of Approval 1st Feb 2013, Project \# Pro00036132). In the present study, 40 fibulae (20 in males, 20 in females) in 20 adult patients (10 males [mean: 48.0; range: 22-72], 10 females [mean: 64.2; range: 57-77]) were studied. The 20 patients underwent preoperative CT imaging at the University of Alberta Hospital before FVFF reconstruction.

\section{CT scanning}

The patients were imaged using a SOMATOM Definition Flash medical CT system (Siemens, Oakville, Canada). Imaging was performed with a $120 \mathrm{kV}$ tube voltage, $90 \mathrm{~mA}$ tube current, $1 \mathrm{~mm}$ slice thickness, and $0.66 \mathrm{~mm}$ pixel size.

\section{Image processing for measurements}

First, DICOM data were imported into Mimics 13.1 (Materialise, Leuven, Belgium), and the fibula was modeled using the CT threshold values (Min, 226; Max, 3071) for the bone data (Mimics default CT values). The model was exported as STL data. Next, the 3D fibula image from the STL file was viewed on screen using Geomagic Qualify 2013 (Geomagic, Morrisville, NC, USA). Finally, cross-sections were created for observation, and the measurements were taken as described below at each cross-section.

\section{Measurements \\ Cross-section}

The apex of the head of the fibula was point A, and that of the lateral malleolus was point $\mathrm{G}$. The length between these two points was divided into six equal segments, and each of the dividing points from the apex of the head of the fibula was denoted B, C, D, E, and F (Figure 1). A cross-section perpendicular to the axis of the fibula was then created at each of points B, C, D, E, and F, and these sections were denoted as B, C, D, E, and F. Geomagic Qualify 2013 was used to define these sections and produce the measurements described below.

\section{Length of fibula}

The full length of the fibula was measured from the apex of the head of the fibula (point A) to the apex of the lateral malleolus (point G) (Figure 1). To confirm that sections $\mathrm{C}, \mathrm{D}$, and $\mathrm{E}$ were part of the bone graft region, their distances from the apex of the lateral malleolus were calculated from the full length of the fibula.

\section{Width from the margins of the fibula to their opposing surfaces}

To obtain an overview of the entire fibula, length measurements of the fibula cross-sections at B, C, D, E, and $\mathrm{F}$ were performed, in accordance with the measurement system used by Matsuura [13]. As shown in Figure 2, the anterior border was defined as point a, the medial crest was defined as point $\mathrm{b}$, and the lateral border was defined as point c. A perpendicular line was drawn from point a to line $\mathrm{b}-\mathrm{c}$, and the intersection of its extension with the posterior aspect was defined as point d. Similarly, a perpendicular line was drawn from point c to line $a-b$, and the intersection of its extension with the medial aspect was defined as point e. A perpendicular line was drawn from point $\mathrm{b}$ to line $\mathrm{a}-\mathrm{c}$, and the intersection

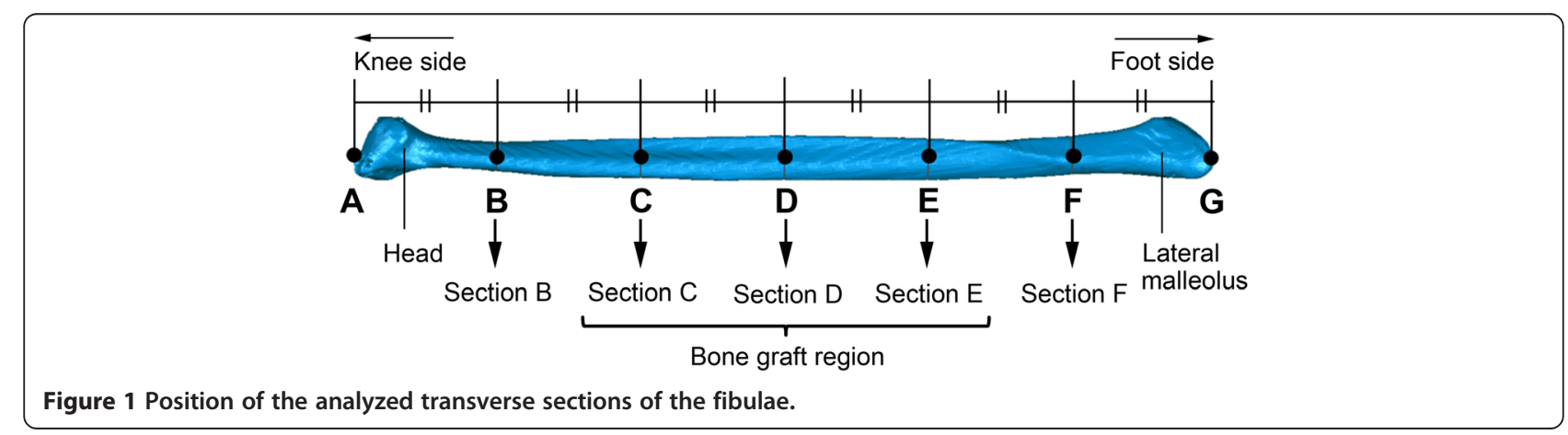




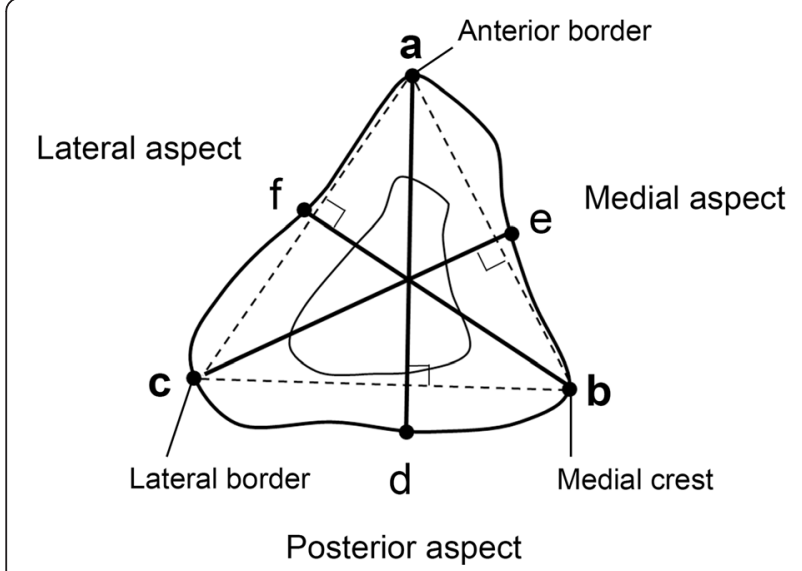

Figure 2 Measuring the width from the margins of the fibula to their opposing surfaces.

of its extension with the lateral aspect was defined as point $f$. The distances $a-d, c-e$, and $b-f$ were measured.

\section{Cross-section shapes}

Drawing on the method of Matsuura et al. [13], the shapes of the cross-sections at C, D, and $\mathrm{E}$ of the bone graft region were categorized into three types: triangular, quadrilateral, and irregular (Figure 3).

\section{Height and width related to the long axis of installation of the implant}

Drawing on the method of Frodel et al. [14], the height and width at sections $\mathrm{C}, \mathrm{D}$, and $\mathrm{E}$ were measured with reference to the long axis of installation of the implant (Figure 4).

\section{Length of available bone volume for the osseointegrated implant installation}

The length available for implantation with the standard (4.3 $\mathrm{mm} \phi)$ and narrow (3.5 $\mathrm{mm} \phi)$ implants at sections $\mathrm{C}, \mathrm{D}$, and $\mathrm{E}$ was measured. As shown in Figure 5, dimension to account for $1 \mathrm{~mm}$ bone margin on both sides of the implant (lateral and medial aspects) was defined, and the anterior border was adjusted to the defined bone level.

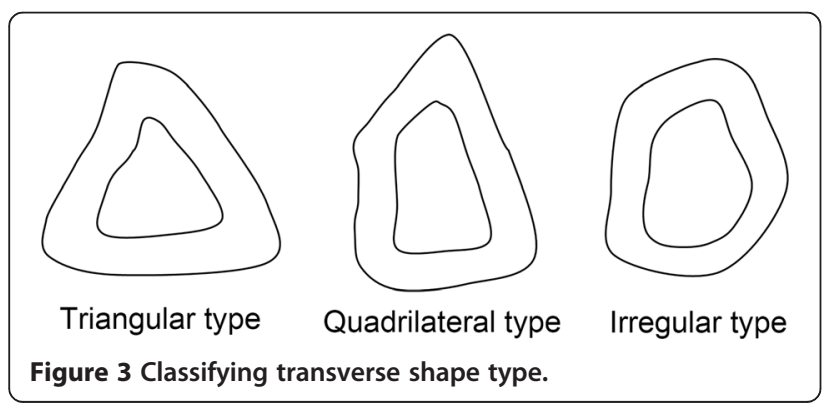

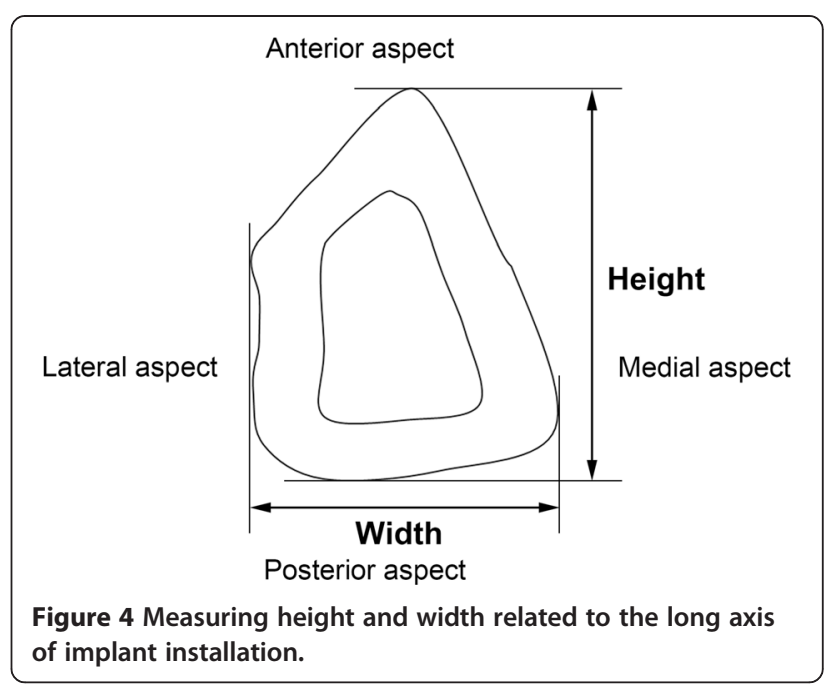

\section{Statistical analysis}

Statistical analysis was performed using SPSS (IBM, Armonk, NY, USA). For all data, the Bonferroni test was used to compare the differences between each section or each measured site, and Student's $t$-test was used to examine sex differences.

\section{Results}

\section{Length of the fibula}

Table 1 shows the results of the measurements of fibula length from the apex of the head of the fibula (point A) to the apex of the lateral malleolus (point G), as well as the calculated lengths from the apex of the lateral malleolus to each of the sections $B, C, D, E$, and F. The mean fibula length, which was $387.4 \pm 23.7 \mathrm{~mm}$ in male patients and $361.5 \pm 12.3 \mathrm{~mm}$ in female patients, was significantly longer in the male patients than in the female patients.

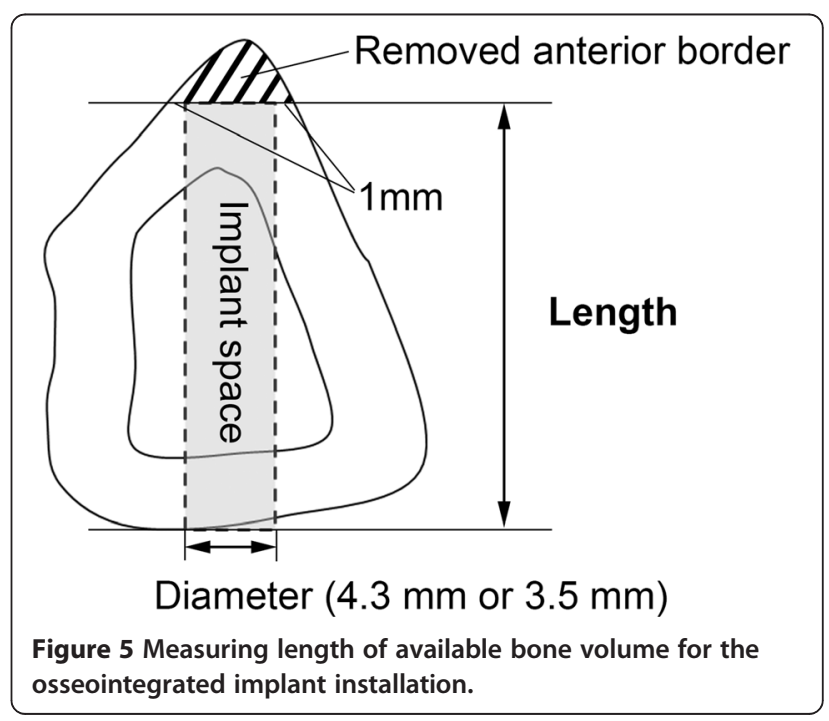


Table 1 Length of Fibula (mm)

\begin{tabular}{|c|c|c|c|c|c|c|}
\hline \multirow[t]{2}{*}{ Gender } & \multirow[t]{2}{*}{ Full length* } & \multicolumn{5}{|c|}{ Position (Length from the apex of lateral malleolus) } \\
\hline & & Section B & Section C & Section D & Section E & Section $\mathrm{F}$ \\
\hline Male & $387.4 \pm 23.7$ & $322.3 \pm 19.7$ & $258.3 \pm 15.8$ & $193.7 \pm 11.8$ & $129.1 \pm 7.9$ & $64.6 \pm 3.9$ \\
\hline Female & $361.5 \pm 12.3$ & $301.3 \pm 10.2$ & $241.0 \pm 8.2$ & $180.8 \pm 6.1$ & $120.5 \pm 4.1$ & $60.3 \pm 2.0$ \\
\hline
\end{tabular}

*The mean fibula length was significantly longer in the male patients than in the female patients $(P<0.01)$.

Investigations of the position of each section showed that the lengths from the apex of the lateral malleolus to sections F, E, D, C, and B were $64.6 \pm 3.9 \mathrm{~mm}, 129.1 \pm$ $7.9 \mathrm{~mm}, 193.7 \pm 11.8 \mathrm{~mm}, 258.3 \pm 15.8 \mathrm{~mm}$, and $322.3 \pm$ $19.7 \mathrm{~mm}$, respectively, in the male patients and $60.3 \pm$ $2.0 \mathrm{~mm}, 120.5 \pm 4.1 \mathrm{~mm}, 180.8 \pm 6.1 \mathrm{~mm}, 241.0 \pm 8.2$ $\mathrm{mm}$, and $301.0 \pm 10.2 \mathrm{~mm}$, respectively, in the female patients. FVFF is performed using an area approximately $20 \mathrm{~cm}$ in length, beginning approximately $9 \mathrm{~cm}$ from the malleolus. Therefore, the results confirmed that sections $\mathrm{C}, \mathrm{D}$, and $\mathrm{E}$ in both the male and female patients were part of the potential bone harvest region.

Width from margins of the fibula to their opposing surfaces Figure 6 shows the results of a comparison of the widths from the margins (anterior border, medial crest, lateral border) to their opposing surface (posterior surface, medial surface, lateral surface) at sections B, C, D, E, and F. At sections $C, D$, and $E, a-d$ in both the male and female patients was significantly longer than $b-f$ and $\mathrm{c}-\mathrm{e}$. At section $\mathrm{B}, \mathrm{a}-\mathrm{d}$ in both the male and female patients was significantly longer than $b-f$, but it was not significantly different from $\mathrm{c}-\mathrm{e}$. At section $\mathrm{E}, \mathrm{b}-\mathrm{f}$ tended to be the longest in both the male and female patients. These results showed that $\mathrm{a}-\mathrm{d}$ at sections $\mathrm{C}, \mathrm{D}$, and $\mathrm{E}$ (the bone graft region) was the longest compared with the other widths.

A comparison of sections B, C, D, E, and F between male and female patients showed that the values for the male patients were significantly greater at all sites $(\mathrm{P}<0.01)$.

\section{Cross-section shapes}

Figure 7 shows the evaluation by shape at sections C, D, and $\mathrm{E}$. In the male patients, the shapes were triangular in $65 \%$, quadrilateral in $20 \%$, and irregular in $15 \%$ of the patients at section C; triangular in $60 \%$, quadrilateral in $35 \%$, and irregular in $5 \%$ of the patients at section D; and triangular in $35 \%$, quadrilateral in $5 \%$, and irregular in $60 \%$ of the patients at section E. In the female patients, the shapes were triangular in $70 \%$, quadrilateral in $30 \%$, and irregular in $0 \%$ of the patients at section C; triangular in $45 \%$, quadrilateral in 50\%, and irregular in 5\% of the patients at section D; and triangular in $15 \%$, quadrilateral in $35 \%$, and irregular in $50 \%$ of the patients at section E. These results showed that section $C$ (towards the head of the fibula) was often triangular in both the male and female patients. Section D tended to be both triangular and quadrilateral in both the male and female patients. Section E (towards the lateral malleolus) often tended to be irregular.

\section{Height and width related to the long axis of implant installation}

Measurements were made of the fibula height and width as they relate to the long axis of implant installation at sections C, D, and E. A comparison of the heights at each section showed no significant differences in the male patients, and the value was significantly greater at section $C$ than at section $E$ in the female patients (Figure 8). A comparison of the widths at each section showed that values were significantly greater at section $D$ than at sections $C$ and $E$ in both the male

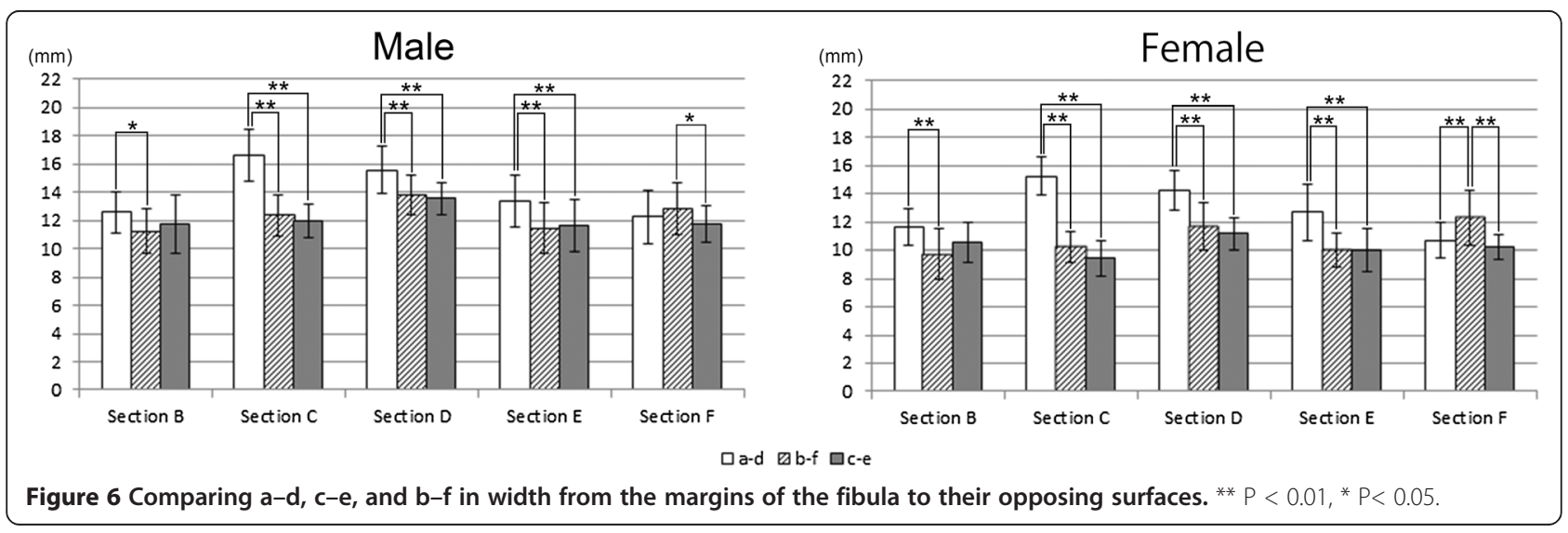




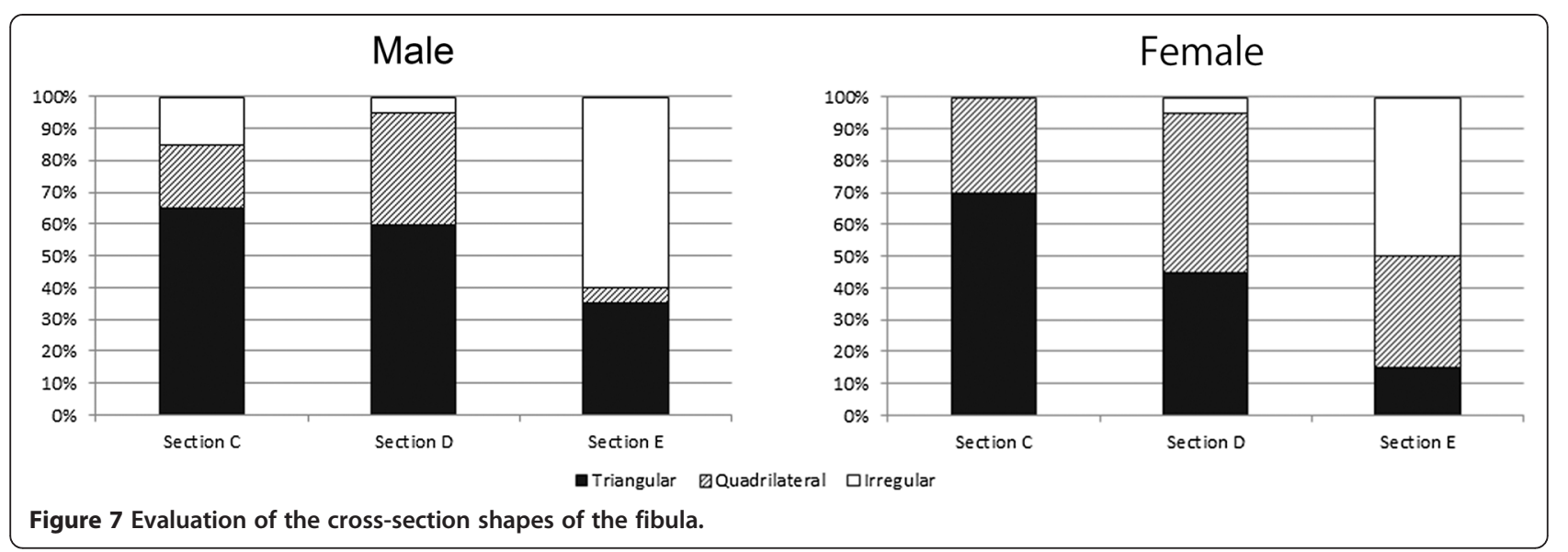

and female patients (Figure 9). A comparison of both height and width at each section between male and female patients showed that the male dimensions were significantly larger than the female dimensions at all sites $(\mathrm{P}<$ 0.01 ).

Length of available bone volume for the osseointegrated implant installation

Table 2 shows the measurements of the length of available bone volume assuming the installation of regular $(4.3 \mathrm{~mm} \phi)$ and narrow $(3.5 \mathrm{~mm} \phi)$ implants. For the regular implants, the lengths at sections $\mathrm{C}, \mathrm{D}$, and $\mathrm{E}$ were $12.9 \pm 2.2 \mathrm{~mm}, 13.4 \pm 1.7 \mathrm{~mm}$, and $14.5 \pm$ $1.5 \mathrm{~mm}$, respectively, in the male patients and $10.8 \pm$ $2.0 \mathrm{~mm}, 10.9 \pm 1.1 \mathrm{~mm}$, and $12.0 \pm 1.1 \mathrm{~mm}$, respectively, in the female patients. For the narrow implants, the lengths at sections $\mathrm{C}, \mathrm{D}$, and $\mathrm{E}$ were $14.1 \pm 2.1$ $\mathrm{mm}, 14.3 \pm 1.6 \mathrm{~mm}$, and $14.8 \pm 1.5 \mathrm{~mm}$, respectively, in the male patients and $12.0 \pm 2.0 \mathrm{~mm}, 11.9 \pm 1.1 \mathrm{~mm}$, and $12.5 \pm 1.1 \mathrm{~mm}$, respectively, in the female patients.
A comparison of these lengths at each section showed that with the regular diameter implant $(4.3 \mathrm{~mm} \phi)$, the length of available bone volume at section $\mathrm{E}$ was significantly greater than that at section $\mathrm{C}$ in both the male and female patients (Figure 10a). However, with the narrow diameter implant $(3.5 \mathrm{~mm} \phi)$, there was no significant difference between the sections in the length of the implant space (Figure 10b).

A comparison of the length of available bone volume for the regular $(4.3 \mathrm{~mm} \phi)$ and narrow $(3.5 \mathrm{~mm} \phi) \mathrm{im}$ plants between male and female patients showed that the lengths were significantly greater in male patients than in female patients at all sections $(\mathrm{P}<0.01)$.

\section{Discussion}

FVFF with installation of osseointegrated implants is now routinely performed for jaw reconstruction, and studies have shown high success rates and good functional recovery [6-10]. To achieve improved outcomes with treatments involving fibula implants, surgeons must

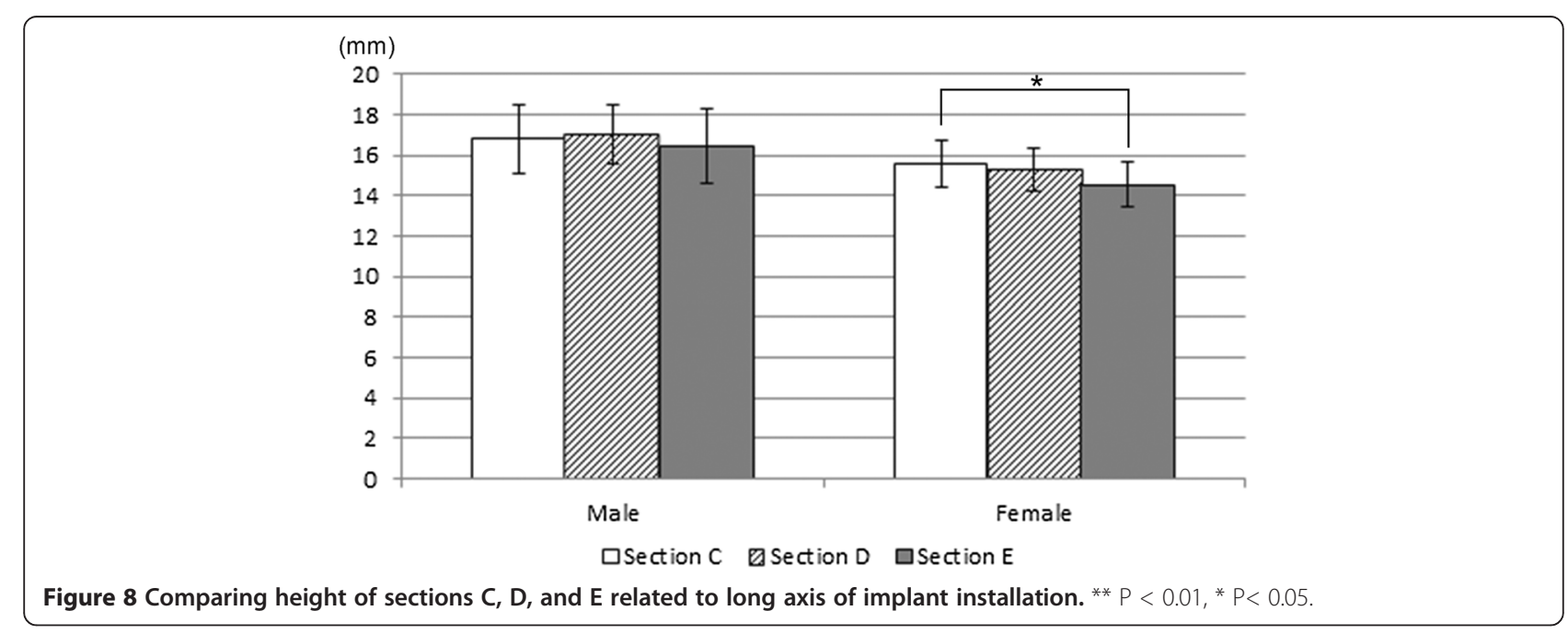




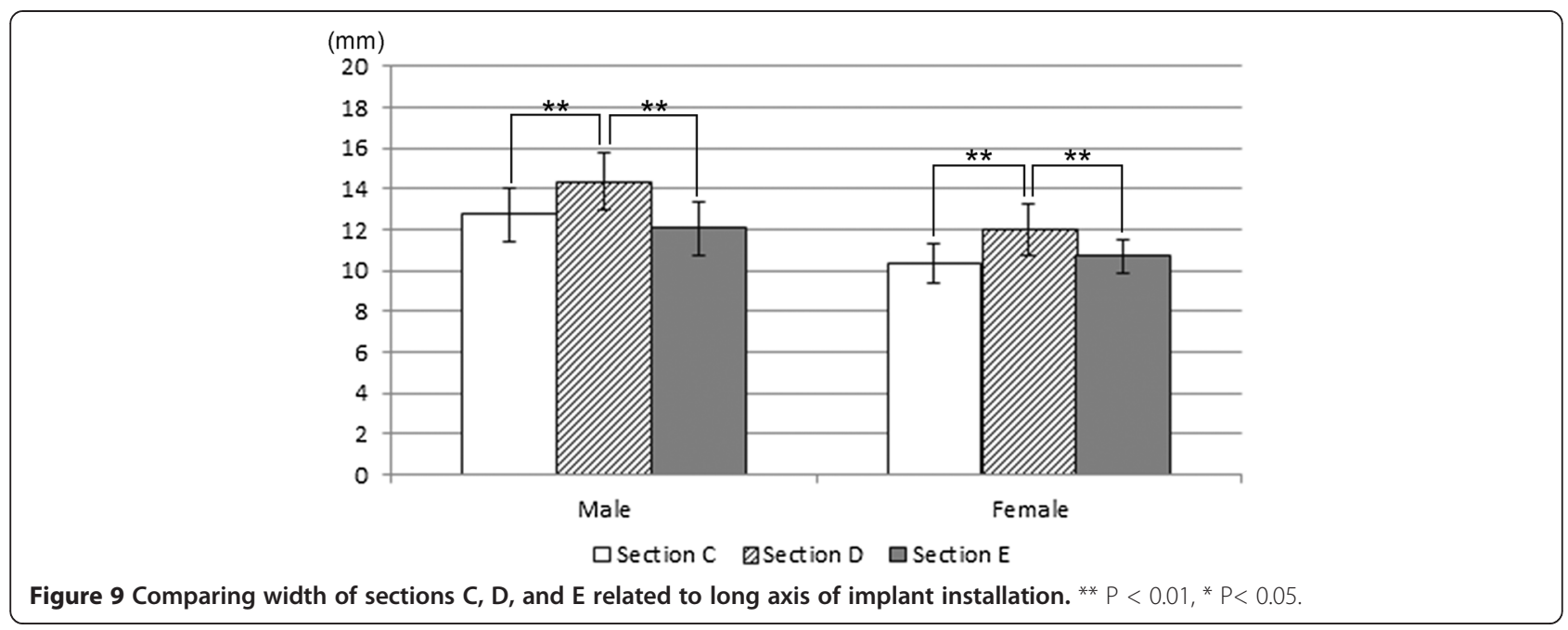

possess an understanding of the shape characteristics of the fibula before the surgery.

The present study involved shape measurements based on data from medical CT imaging of patient fibulae. The advantages of measurements based on CT data are that cross-sections of interest can be easily observed in a non-destructive fashion, and a range of measurements are possible. Four parameters for investigation were established in cross-sections of the fibulae. In examining these measures through an imaging-based process, it is not known how dimensionally accurate the system is in relation to physical measurement on cadavers. The dimensional fidelity of the system is the subject of a study that is underway. Concerns with regard to the imaging study relate to issues such as the particular pixel size in images taken by medical CT, partial volume effects, or other factors. However, it was considered that the measured values can be compared since the values measured were acquired under the same condition. Statistical analyses were performed on differences at different sites, between patients of different sexes and to investigate the fibular shape characteristics. Preoperative planning for implant installation involves the measurement of the available bone volume on CT images and the selection of an appropriately sized implant. Hence, values for the length of available bone volume for osseointegrated implant installation were assessed.

Table 2 Length of available bone volume for the osseointegrated implant installation ( $\mathrm{mm}$ )

\begin{tabular}{lllll}
\hline Diameter of implant & Gender & Length & & \\
\cline { 3 - 5 } & & Section C & Section D & Section E \\
\hline $4.3 \mathrm{~mm}$ (Regular type) & Male & $12.9 \pm 2.2$ & $13.4 \pm 1.7$ & $14.5 \pm 1.5$ \\
& Female & $10.8 \pm 2.0$ & $10.9 \pm 1.1$ & $12.0 \pm 1.1$ \\
$3.5 \mathrm{~mm}$ (Narrow type) & Male & $14.1 \pm 2.1$ & $14.3 \pm 1.6$ & $14.8 \pm 1.5$ \\
& Female & $12.0 \pm 2.0$ & $11.9 \pm 1.1$ & $12.5 \pm 1.1$ \\
\hline
\end{tabular}

\section{Length of fibula}

FVFF is performed using an area approximately $20 \mathrm{~cm}$ in length running from a point approximately $9 \mathrm{~cm}$ from the lateral malleolus [11]. When the positions of sections $\mathrm{B}, \mathrm{C}, \mathrm{D}, \mathrm{E}$, and F from the lateral malleolus were calculated, section $E$ was positioned at $129.1 \pm 7.9 \mathrm{~mm}$ in the male patients and $120.5 \pm 4.1 \mathrm{~mm}$ in the female patients, while section $C$ was positioned at $258.3 \pm 15.8 \mathrm{~mm}$ in the male patients and $241.0 \pm 8.2 \mathrm{~mm}$ in the female patients. Therefore, the positions of sections $\mathrm{C}, \mathrm{D}$, and $\mathrm{E}$ were defined as part of the bone flap region and sections $\mathrm{C}, \mathrm{D}$, and $\mathrm{E}$ were investigated in detail.

\section{Width from the margins of the fibula to their opposing surfaces}

The length of the installed implant is an important factor for implant stability [16]. Therefore, surgeons need to select on area with adequate bone volume for an implant length when installing an implant into the fibula. Osseointegrated implant installation in the fibula is usually performed along the axis from the anterior border towards the posterior surface, using the anterior border as an approximation of the alveolar crest. There are three margins in the fibula (anterior border, medial crest, lateral border) that could be used as the alveolar crest depending on the orientation of the fibula in relation to the vascular pedicle. Of particular interest is whether the possibility of using a long implant is greater when installing an implant along the axis from the anterior border than when doing so from the other margins. A comparison was made of the widths from these three margins to their opposing surfaces at sections B, C, D, E, and $F$. The measurements showed that, at sections $C, D$, and $E, a-d$ was significantly longer than the other widths. This trend was not as marked at section $\mathrm{B}$ as it was at sections $\mathrm{C}, \mathrm{D}$, and $\mathrm{E}$. At section $\mathrm{F}, \mathrm{b}-\mathrm{f}$ was significantly longer than the other widths. These results suggest 

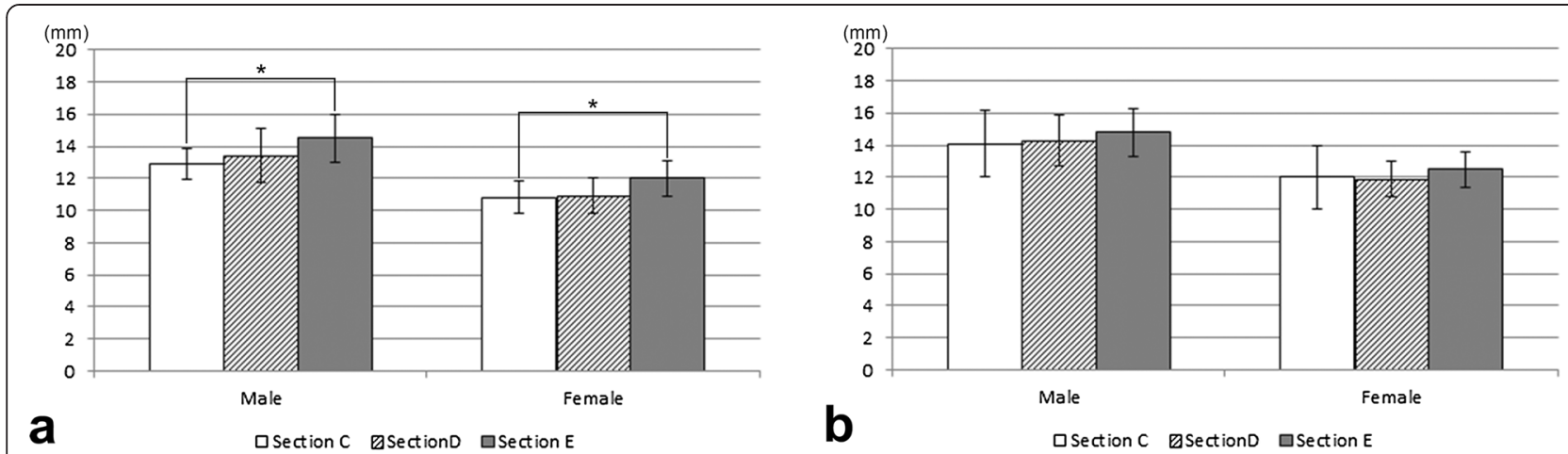

Figure 10 Comparing length of available bone volume in sections C, D, and E for the $4.3 \mathrm{~mm}$ diameter (a) and $3.5 \mathrm{~mm}$ diameter (b) implant installation. ${ }^{* *} P<0.01,{ }^{*} P<0.05$.

that the region containing sections $C, D$, and $E$, which is used during bone flap reconstructions, provides a suitable axis of installation when considering implant stability, due to the distance from the anterior border to the posterior surface being greater than elsewhere.

\section{Cross-section shape}

Anatomy textbooks [17] describe the fibular body as a triangular column and state that the cross-section of the fibula has 4 apices: the anterior border, the lateral border, the interosseous border, and the medial crest. To conduct more realistic evaluations in this study, the evaluation methods of Matsuura et al. [13] were used, and sections $\mathrm{C}, \mathrm{D}$, and $\mathrm{E}$ were categorized into three types: triangular, quadrilateral, and irregular. An understanding of shape trends at each site is valuable when establishing a treatment plan for fibula bone transplantation to the lower jaw and implant installation into the fibula. In the present study, section $\mathrm{C}$ was often triangular, and section $\mathrm{E}$ tended to be irregular. In other words, the study showed that the section closer to the head of the fibula is commonly triangular, and that towards the lateral malleolus tends to be irregular. Furthermore, compared with the quadrilateral and irregular shapes, the triangular shape has a more acute angle at the anterior border. Triangular shapes are better subjected to an elective ostectomy of the bony crest when installing implants. The reason for trimming the bony crest is to create a platform of bone of adequate width to accommodate the implant.

Height and width related to implant long axis of installation The fibula height and width at sections C, D, and E were measured with reference to the implant long axis of installation. In terms of height, a difference between sections $C$ and $\mathrm{E}$ was observed in the female patients $(\mathrm{P}<0.05)$, but no other significant differences were seen among sections. In terms of width, however, the fibulae at section $\mathrm{D}$ were significantly wider than those at the other sections $(\mathrm{P}<0.01)$. Accordingly, there were no marked differences in height at the site of the fibula implant to be inserted, and the central portion of the fibula tended to be wider. This may be useful information when selecting the donor site on the fibula.

\section{Length of available bone volume for osseointegrated implant installation}

When installing implants into the fibula, surgeons need to consider the characteristics of the available bone volume for installation. To perform more realistic measurements, the installation of regular $(4.3 \mathrm{~mm} \phi)$ or narrow (3.5 $\mathrm{mm} \phi)$ osseointegrated implants was assumed. When installing implants into the fibula, preparing the site involves trimming the fibula alveolar crest to secure adequate width to install an osseointegrated implant. In the present study, the trimmed portion from the area measured was excluded, leaving a margin of $1 \mathrm{~mm}$ on both sides (lateral and medial aspects) of the implant.

The measurements from the present study were made using patient CT images, raising the possibility of measurement errors from partial volume effects or the particular pixel size used in the diagnostic CT imaging. The measurement error is likely small since the anterior border section, where errors are prone to occur, was excluded from the area measured. In addition, as CT imaging is normally used to select the appropriate implant for installation when planning implant treatment, it was considered that the values shown in this study are clinically meaningful. A comparison of the values at each section, assuming installation of a regular implant $(4.3 \mathrm{~mm} \phi)$, showed that, for both the male and female patients, were greater at section $\mathrm{E}$ than at section $\mathrm{C}$. This suggests that sites closer to the lateral malleolus allow the installation of longer implants than do those towards the fibula head. When comparing the dimension of the bone to the implant long axis of installation, no bone height differences were seen at the various sites in the male patients, whereas in the female patients, the heights were significantly greater at sites near the head of the fibula than at those near the lateral malleolus. These results are attributed to differences in 
shape; at sites near the head of the fibula, the anterior border tends to be triangular with an acute angle rather than quadrilateral or irregular, so that sites near the head of the fibula involve more trimming of the bony crest prior to implant installation.

\section{Gender differences}

All the measurements in the present study showed larger dimensions in the male patients than in the female patients. Therefore, this difference in available bone volume between the genders needs to be taken into consideration when installing an osseointegrated implant.

\section{Conclusion}

In the present study, the fibula was investigated anatomically using patient $\mathrm{CT}$ images. The present study provides valuable information for the optimal site of installation of osseointegrated implants in FVFF reconstructions.

\section{Abbreviations}

FVFF: Free vascularized fibular flaps.

\section{Competing interests}

The authors declare that they have no competing interests.

\section{Authors' contributions}

YI, SM, JH, DOC, HS and JW all conceived the study. SM, HS and JW created the approval ethics. YI and JW were responsible for conception of study in detail. YI collected and analyzed data, and wrote the manuscript. All authors read the manuscript and approved the final manuscript.

\section{Acknowledgements}

We thank Dr. Samer Adeeb and Alexandra Trovato of the Department of Civil and Environmental Engineering, University of Alberta for providing measurement advice. We also thank the Institute for Reconstructive Sciences in Medicine (iRSM), Alberta Health Services/Covenant Health/University of Alberta for their support of the study. This work was supported in part by a Grant-in-Aid for Scientific Research (C) (No. 24592848 to Y.I.) from Japan Society for the Promotion of Science (JSPS).

\section{Author details}

${ }^{1}$ Department of Developmental and Regenerative Dentistry, School of Life Dentistry at Tokyo, The Nippon Dental University, 1-9-20 Fujimi, Chiyoda-ku, Tokyo 102-8159, Japan. ²Department of Anatomy, Tokyo Dental College, 2-9-18 Misaki-cho, Chiyoda-ku, Tokyo 101-0061, Japan. ${ }^{3}$ Division of Otolaryngology Head and Neck Surgery, Department of Surgery, Faculty of Medicine and Dentistry, University of Alberta, 1E4 WMC, 8440-112 Street, Edmonton, Alberta T6G 2B7, Canada. ${ }^{4}$ Institute for Reconstructive Sciences in Medicine (iRSM), Alberta Health Services/Covenant Health/University of Alberta, 1W-02, 16940-87 Avenue, Edmonton, Alberta T5R 4H5, Canada.

Received: 27 October 2014 Accepted: 15 January 2015

Published online: 03 February 2015

\section{References}

1. Taylor Gl, Miller GD, Ham FJ. The free vascularized bone graft. A clinical extension of microvascular techniques. Plast Reconstr Surg. 1975;55(5):533-44.

2. Hidalgo DA. Fibula free flap: a new method of mandible reconstruction. Plast Reconstr Surg. 1989;84(1):71-9.

3. Lyberg T, Olstad OA. The vascularized fibular flap for mandibular reconstruction. J Craniomaxillofac Surg. 1991;19(3):113-8.

4. Zlotolow IM, Huryn JM, Piro JD, Lenchewski E, Hidalgo DA. Osseointegrated implants and functional prosthetic rehabilitation in microvascular fibula free flap reconstructed mandibles. Am J Surg. 1992;164(6):677-81.
5. Lee JH, Kim MJ, Kim JW. Mandibular reconstruction with free vascularized fibular flap. J Craniomaxillofac Surg. 1995;23(1):20-6.

6. Roumanas ED, Markowitz BL, Lorant JA, Calcaterra TC, Jones NF, Beumer 3rd J. Reconstructed mandibular defects: fibula free flaps and osseointegrated implants. Plast Reconstr Surg. 1997;99(2):356-65.

7. Anne-Gaëlle B, Samuel S, Julie B, Renaud L, Pierre B. Dental implant placement after mandibular reconstruction by microvascular free fibula flap: current knowledge and remaining questions. Oral Oncol.

2011;47(12):1099-104.

8. Logan H, Wolfaardt J, Boulanger $\mathrm{P}$, Hodgetts B, Seikaly H. Exploratory benchtop study evaluating the use of surgical design and simulation in fibula free flap mandibular reconstruction. J Otolaryngol Head Neck Surg. 2013:42:42.

9. Roumanas ED, Garrett N, Blackwell KE, Freymiller E, Abemayor E, Wong WK, et al. Masticatory and swallowing threshold performances with conventional and implant-supported prostheses after mandibular fibula free-flap reconstruction. J Prosthet Dent. 2006;96(4):289-97.

10. Seikaly H, Maharaj M, Rieger J, Harris J. Functional outcomes after primary mandibular resection and reconstruction with the fibular free flap. J Otolaryngol. 2005;34(1):25-8.

11. Shindo M, Fong BP, Funk GF, Karnell LH. The fibula osteocutaneous flap in head and neck reconstruction. Arch Otolaryngol Head Neck Surg. 2000;126(12):1467-72.

12. Germain MA, Gomez NG, Demers G, Hureau J. Anatomic basis of mandibular reconstruction by free vascularised fibular graft. Surg Radiol Anat. 1993;15(3):213-4.

13. Matsuura M, Ohno K, Michi K, Egawa K, Takiguchi R. Clinicoanatomic examination of the fibula: anatomic basis for dental implant placement. Int J Oral Maxillofac Implants. 1999;14(6):879-84.

14. Frodel Jr JL, Funk GF, Capper DT, Fridrich KL, Blumer JR, Haller JR, et al. Osseointegrated implants: a comparative study of bone thickness in four vascularized bone flaps. Plast Reconstr Surg. 1993;92(3):449-55.

15. Seikaly H, Chau J, Li F, Driscoll B, Seikaly D, Calhoun J, et al. Bone that best matches the properties of the mandible. J Otolaryngol. 2003;32(4):262-5.

16. Adell R, Lekholm U, Rockler B, Brånemark PI. A 15-year study of osseointegrated implants in the treatment of the edentulous jaw. Int J Oral Surg. 1981;10(6):387-416.

17. Drake RL, Mitchell AWM, Vogl AW. Gray's Anatomy for Students, 2nd Edition. Amsterdam: Elsevier; 2009.

\section{Submit your next manuscript to BioMed Central and take full advantage of:}

- Convenient online submission

- Thorough peer review

- No space constraints or color figure charges

- Immediate publication on acceptance

- Inclusion in PubMed, CAS, Scopus and Google Scholar

- Research which is freely available for redistribution 